\title{
EFFECT OF HOT PRESSING MODIFICATION ON SURFACE PROPERTIES OF RUBBERWOOD (HEVEA BR ASILIENSIS)
}

\author{
Zhipeng Zhu, Dengyun Tu, Ziwei Chen, Chuanfu Chen, Qiangfang Zhou \\ South China Agricultural University \\ China \\ (Received April 2020)
}

\begin{abstract}
This research aims to investigate the effect of thermal modification by hot pressing on surface characteristics of rubberwood. For this purpose, rubberwood specimens were thermally modified by hot pressing in an open system at three different temperatures $\left(170,185\right.$, and $\left.200^{\circ} \mathrm{C}\right)$ for two different durations ( 1.5 or $3 \mathrm{~h}$ ). Based on the results, the values of chromatic aberration $(\Delta \mathrm{E})$, contact angle and glossiness increased, and roughness decreased with increasing temperature and enlarging duration further. Although the contact angle had increased, it was still less than $90^{\circ}$. This aesthetic surface of rubberwood could be retained by using transparent organic coatings. The thermally modified rubberwood with excellent performance could be used as a material for solid wood flooring, wallboard, and furniture applications.
\end{abstract}

KEYWORDS: Thermal modification, rubberwood, surface characteristics, compression ratio.

\section{INTRODUCTION}

Rubberwood (Hevea brasiliensis) is one of the most important wooden raw materials in South East Asia. The fundamental purpose of planting rubberwood is harvesting latex. Generally, the rubber trees will be probably felled when they are around 20 years due to a decrease in latex production. Thus, rubberwood is an important by-product resource and commonly used as industrial raw materials (Jiang et al. 2019). The rubber tree cultivated in Thailand is felled about 300 thousand $\mathrm{hm}^{2}$ every year, and rubberwood exported to China accounts for $90 \%$ above (Cheng et al. 2017). Thus, it is one kind of sustainable development of artificial forest commodity material. Rubberwood, which features beautiful textures and excellent machining performance, is suitable for making wooden products such as furniture and solid wood flooring. However, rubberwood is extremely prone to mildew, moth, and decay, owing to a higher content of nutrients in the wood, about $8 \%$ of starch and free sugar (Jie et al. 2018, Li et al. 2012). Thermal modification is an effective method to enhance dimensional stability and biological durability, nowadays, without 
the use of chemicals to improve the applied value of low nature wood (Cademartori et al. 2015). Therefore, it is necessary to conduct thermal modification to improve the quality of rubberwood and enhance its utilization value.

The thermal modification technology can also change the color of the wood surface. The wood surface is darkened after heat treatment. The color changes in the heat-treated wood surface were due to the degradation products from the hemicellulose and lignin. Previously research showed that the color of heat-treated wood was mainly affected by some factors, such as temperature, duration, wood species, and moisture content (Ding et al. 2017, Esteves et al. 2008, Yildiz et al. 2006, Yu et al. 2010). Generally, the surface color of heat-treated wood changed with the increase of heat treatment temperature and duration. The deep color is appealing to customers because it is similar to the rare wood, such as sandalwood and rosewood.

However, the mechanical strength of heat-treated wood typically reduced significantly by using traditional thermal modification techniques, due to the thermal degradation of the chemical components in the cell walls. The bending strength, modulus of elasticity, compression strength, and impact bending strength of rubberwood heat-treated at $230^{\circ} \mathrm{C}$ for $3 \mathrm{~h}$ decreased $63.74 \%$, $41.22 \%, 26.16 \%$, and 57.07\%, respectively, compared with the control groups (Zhao et al. 2019). In general, the mechanical properties of heat-treated wood gradually decreased with the increase of the heat treatment temperature and duration. The primary factor leading the reduction of mechanical properties was the degradation of hemicellulose and parts of the amorphous cellulose (Cai et al. 2019, Korkut et al. 2015). Another study on poplar wood (Populus tomentosa), the wood was thermally treated at $195^{\circ} \mathrm{C}$ for 3 hours and then subjected to hot pressing at $160^{\circ} \mathrm{C}$. The results showed that the surface hardness, modulus of elasticity, and modulus of rupture of treated wood increased by more than 30\% (Du et al. 2013). This combined modification method can effectively compensate the loss of mechanical properties caused by heat treatment.

To improve the physical and mechanical properties of heat-treated rubberwood, the rubberwood could be compressed with a relatively low compression ratio, and then it was heattreated under a pressure of about $1 \mathrm{MPa}$ by hot pressing. The physical and mechanical properties of the thermally modified rubberwood were improved significantly due to the compression (Zhou et al. 2019). However, during the heat treatment process, the surface characteristics of rubberwood have changed evidently, which has a great influence on its practical applications. Thus, it is necessary to research this aspect. In this study, the effects of heat treatment temperature and duration on the surface characteristics of heat-treated rubberwood were investigated. The obtained results could be effectively guided the practical productions of the thermally modified rubberwood and realized its high value-added utilization.

\section{MATERIALS AND METHODS}

\section{Wood material}

Rubberwood (Hevea brasiliensis) was harvested from Thailand. Rubberwood samples used in this study, with the moisture content of $14 \%$ and air-dried densities of $0.72 \mathrm{~g} \cdot \mathrm{m}^{-3}$, were purchased from the wood market. Wood board samples, measuring $300 \times 105 \times 20 \mathrm{~mm}$ (longitudinal (L) $\times$ tangential $(\mathrm{T}) \times$ radial $(\mathrm{R})$ direction), were prepared. Seven groups of samples (six for heat treatment by hot pressing and one for control) were prepared, and each group had 18 samples.

\section{Thermal modification}

The thermal treatment of rubberwood was performed with a laboratory-type single-opening hot press (BY302 $\times 2 / 15$, Suzhou Xinxieli, China). Three different temperatures $(170,185$, and 
$200^{\circ} \mathrm{C}$ ) and two different durations $(1.5,3 \mathrm{~h}$ ) were selected for the heat treatment of rubberwood. The heat treatment process was divided into four stages.

In the first phase, the upper and lower hot plates were heated to the target temperature $\left(170,185\right.$ and $\left.200^{\circ} \mathrm{C}\right)$, then the samples were placed on the lower hot plate. To control the target thickness of heat-treated wood, two $18 \mathrm{~mm}$ thick metal plates were placed on the lower hot plate on both sides of the samples. The hot-press was closed so that the upper surface of the sample had contact with the upper hot plate. Until the core temperature of the samples reached the target temperature, the samples were compressed. In the second phase, the pressure increased to $14 \mathrm{MPa}$ in $30 \mathrm{sec}$ and kept $3 \mathrm{~min}$, and the wood was compressed to target thickness (18 $\mathrm{mm}$ ) by using a distance stop. The compression ratio of wood was $10 \%$. In the third phase, the pressure decreased to $2 \mathrm{MPa}$, and the wood samples were heat-treated at the target temperature for 1.5 or $3 \mathrm{~h}$. In the last phase, the hot plates were cooled down to room temperature by introducing the flowing water into the hot plates for 30 min under the pressure of $2 \mathrm{MPa}$, and then the wood samples were taken away from the hot-press.

In order to determine the surface properties of heat-treated rubberwood, the treated and control samples were cut into small clear samples with dimensions of $50(\mathrm{~L}) \times 50(\mathrm{~T}) \times 18(\mathrm{R})$ $\mathrm{mm}$. All the samples were conditioned at $20^{\circ} \mathrm{C}$ and $65 \%$ relative humidity for 2 months prior to further testing. Surface performance tests were conducted in a laboratory with $25^{\circ} \mathrm{C}$ and $60 \%$ relative humidity from August to November 2019.

\section{Chromatic aberration}

The color measurements were measured according to GB/T 3979 (2008). The changes in surface color of the heat-treated rubberwood samples were measured by automatic colorimeter (Model:SC-80C, Zhuhai Tian Chuang, China) with D65 illuminant and a $10^{\circ}$ standard observer. Ten replicates were used for each group, and the average value was calculated.

The values of $L^{*}, a^{*}$, and $b^{*}$ of the samples were measured at five different locations on each. $\Delta \mathrm{E}^{*}$ was used to indicate the difference between the color of the treated samples and the color of the control in this study. It had embodied the greater difference between the measured object and the control color that $\Delta \mathrm{E}^{*}$ value was larger. And $\Delta \mathrm{E}$ was calculated according to Eq. 1 , and the average value was calculated:

$$
\Delta E^{*}=\sqrt{\left(\Delta L^{*}\right)^{2}+\left(\Delta a^{*}\right)^{2}+\left(\Delta b^{*}\right)^{2}}
$$

where: $L^{*}$ - the brightness ranging from black (0) to white (100), $a^{*}-$ the color coordinate from red (positive) to green (negative), $\mathrm{b}^{*}$ - the color coordinate from yellow (positive) to blue (negative).

\section{Contact Angle}

The water contact angle of the wood surface was measured according to GB/T 30693 (2014). The water drop size was $4 \mu 1$. The datum after the water droplet contacts the wood surface for $15 \mathrm{~s}$ was recorded. Five replicates were used for each group, and the contact angles were measured at five different points of the same sample surface, and the average value was calculated.

\section{Surface roughness}

The stylus method was a well-accepted contact technique to evaluate the surface roughness of wood samples. Hence the surface roughness of the samples parallel to the fiber direction was measured by the stylus method according to DIN EN ISO 4287 (2009). The samples used for roughness tests were polished with 500 purpose sandpaper, and the values of the same measured 
position were recorded before and after polishing. Five replicates were used for each group, and the surface roughness was measured at five different points of the same sample surface, and the average value was calculated. Three roughness parameters, including mean arithmetic deviation of profile $\left(R_{a}\right)$ which is the average distance from the profile to the mean line over the length of assessment, mean peak-to-valley height $\left(R_{z}\right)$, and maximum roughness $\left(R_{y}\right)$ were used to evaluate surface roughness characteristics of the heat-treated wood samples.

\section{Glossiness}

Glossiness was a measure of the ability of a surface to reflect light. The surface glossiness of wood samples was measured using a gloss meter (KGZ-IC, Tianjin, China). The test angle was set at $60^{\circ}$ according to ASTM standard D 2457-03 (Zhao et al. 2019). The samples for the glossiness tests were polished with 500 purpose sandpaper, and the values of the same measured position were recorded before and after polishing. Five replicates were used for each group, and the glossiness was measured at five different points of the same sample surface, and the average value was calculated. Measurements were carried out at two directions (Parallel to the fiber direction and perpendicular to the fiber direction). The glossiness of parallel to the fiber direction is denoted as GZL, and the glossiness of perpendicular to the fiber direction is denoted as GZT. The unit is GU.

For all parameters, multiple comparisons were first subjected to an analysis of variance (ANOVA), and significant differences between average values of control and treated samples were determined using Duncan's multiple range test at $\mathrm{P}$ value of 0.05 .

\section{RESULTS AND DISCUSSION}

\section{Chromatic aberration}

The surface color of the heat-treated wood and control group are presented in Fig. 1. From Fig. 1, the surface color of heat-treated wood gradually deepened with the increase of heat treatment temperature. With the increase of treatment temperature, the surface color changed from beige to purplish brown. This color was a comfortable, warm tone that had attracted lots of people. Unlike the physical dyeing method, the distribution of the surface color was more uniform by using this thermal modification technique. Changes in color parameters of the untreated control group and the treatment group rubberwood are listed in Tab. 1.

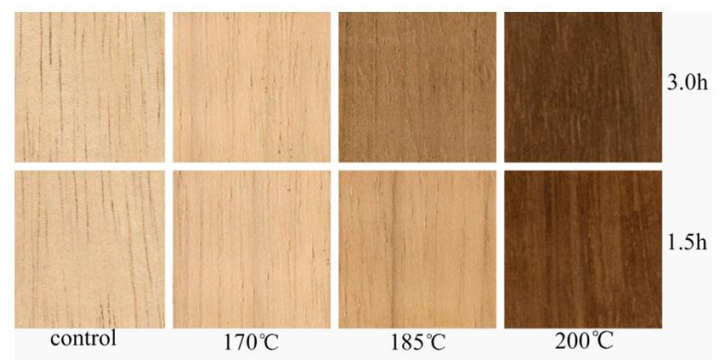

Fig. 1: The color variation of the surface between untreated and thermal modified rubberwood. 
Tab. 1: Color CIE Lab parameters and color difference between untreated and thermal modified rubberwood.

\begin{tabular}{|c|c|c|c|c|c|}
\hline Temperature $\left({ }^{\circ} \mathbf{C}\right)$ & Duration $(\mathbf{h})$ & $\mathbf{L}^{*}$ & $\mathbf{a}^{*}$ & $\mathbf{b}^{*}$ & $\Delta \mathbf{E}^{*}$ \\
\hline- & 0 & 76.16 & 7.69 & 20.36 & $/$ \\
\hline 170 & 1.5 & 62.89 & 11.32 & 24.31 & 14.31 \\
\hline 170 & 3 & 58.46 & 12.46 & 22.73 & 18.48 \\
\hline 185 & 1.5 & 56.60 & 12.78 & 21.82 & 20.26 \\
\hline 185 & 3 & 52.06 & 14.35 & 20.58 & 25.00 \\
\hline 200 & 1.5 & 41.78 & 15.04 & 15.69 & 35.47 \\
\hline 200 & 3 & 37.44 & 14.93 & 13.33 & 40.01 \\
\hline
\end{tabular}

As the heating temperature rose, lightness $\left(\mathrm{L}^{*}\right)$ decreased steadily, and the longer duration, the more obvious the effect. The values of $\mathrm{L}^{*}$ of heat-treated wood decreased by $50.84 \%$ compared with the untreated control group. The parameter $a^{*}$ increased slowly, and the parameter $b^{*}$ decreased slightly, indicating that the color of the heat-treated wood was changed to red and blue with the increase of temperature and duration. As the duration was the same, the $\Delta \mathrm{E}^{*}$ of the treatment group decreased obviously with the increase of treatment temperature. A similar trend was also noted by Sun et al. (2019).

Statistical analysis indicated that the $\mathrm{P}$ values of $\mathrm{L}^{*}$ and $\mathrm{b}^{*}$ with respect to treatment temperature and duration were both less than 0.05 . Thus, both temperature and duration have significant effects on $L^{*}$ and $b^{*}$ values. After comparing the value of $F$, it is evident that treatment temperature is the most significant factor influencing $L^{*}$ and $b^{*}$. The effect of temperature and duration on $\mathrm{a}^{*}$ is not significant, while the effect on $\Delta \mathrm{E}^{*}$ is significant extremely. According to some previous studies, the main reason for the above results was that the thermal cracking reaction between cellulose and hemicellulose. A large number of hydroxyl groups were oxidized into carbonyl and carboxyl groups, thereby deepening the color of the wood. This was similar to the cause of color change in conventional heat-treated wood (Shukla et al. 2014, Srinivas et al. 2012). In addition, the change of wood extract content, especially phenols, caused by thermal modification was also an important factor affecting wood surface color (Esteves et al. 2008).

\section{Contact angle}

Fig. 2 presents the physical picture of the water contact angle of the control group and the treatment group. Fig. 3 shows the actual values of the water contact angle of each treatment group. The water contact angle of heat-treated wood increased with the increase of the treatment temperature and time. Statistical analysis indicated that treatment duration had significant effects on values of contact angle than temperature. Actually, during the heat treatment process, changes in physical and chemical occurred in the surface layers, which resulted in forming a modified surface with new characteristics ( $\mathrm{Li}$ et al. 2011, Qin et al. 2019). During the heat treatment process, the porosity in the wood surface reduced significantly due to the surface densification, which resulted in the increase of the contact angle value of wood surface (Diouf et al. 2011, Unsal et al. 2005). In addition, the number of hydroxyl groups in the wood surface decreased notably because of the thermal degradation of the wood chemical components, which also resulted in the increase of the water contact angle. 


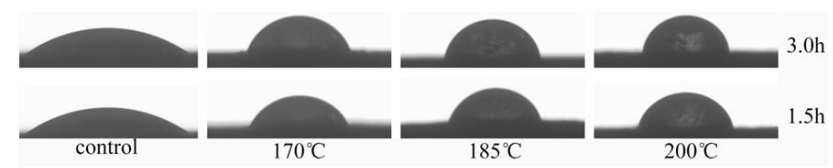

Fig. 2: The picture of water contact angle of the thermally modified rubberwood and untreated wood.

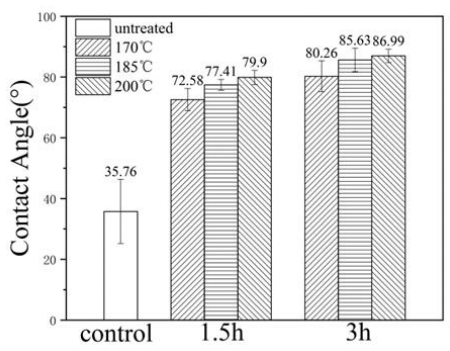

Fig. 3: The actual values of water contact angle of the thermally modified rubberwood and untreated wood.

Nonetheless, changes in the water contact angle of the treatment group was not obvious in this study. The contact angle of the samples heat-treated at $200^{\circ} \mathrm{C}$ for $3 \mathrm{~h}$ was $86.99^{\circ}$, still less than $90^{\circ}$. Because the contact angle value of the water droplet was lower than $90^{\circ}$, the wood surface exhibited hydrophilic property, resulting from the presence of hydroxyl groups in the heat-treated wood surface. In general, the hydrophilic surface was beneficial to make a good bond between the wood and coatings. The surface coatings need to wet, flow or penetrate into the cellular structure of wood to make a good bond between the wood and coatings. The results showed that the wettability of the specimens generally decreased with increasing treatment temperature. Although the effect on bonding strength between wood surface and coatings is small (Aleš et al. 2013).

\section{Surface roughness}

Changes in surface roughness parameters $\left(R_{a}, R_{z}\right.$, and $\left.R_{y}\right)$ of the control group and the treatment group are presented in Fig. 4 (before sanding) and Fig. 5 (after sanding). As shown in Fig. 4, the untreated control group exhibited the highest surface roughness, while the lowest surface roughness was found in the specimens heat-treated at $200^{\circ} \mathrm{C}$ for $3 \mathrm{~h}$. The parameter of $\mathrm{R}_{\mathrm{z}}$ was measured to be $18.01 \mu \mathrm{m}$ for the untreated control wood, while it was determined as $8.05 \mu \mathrm{m}$ for the samples heat-treated at $200^{\circ} \mathrm{C}$ for $3 \mathrm{~h}$ (Fig. 4b). Similar results were found in the $\mathrm{R}_{\mathrm{y}}$ value. The surface-densified wood specimens showed a glossy and smooth appearance after heat treatment processing. During the heat treatment process, the wood fibers in the surface layers were softened that some cell walls in the surface layers were plasticized and compressed, which improves the surface smoothness of the heat-treated wood (Ayrilmis et al. 2019).

In addition, significant changes in $\mathrm{Ra}$ was not observed among the treatment groups. The variation trend of the three parameters becomes clearer after sanding. As shown in Fig. 5, the values of three parameters decreased with increasing treatment temperature and time. When the wood was treated for three hours, the values of $R_{a}$ and $R_{z}$ were almost similar to the untreated control wood. It was distinctly that the three parameters of the treatment groups after sanding 
were higher than those before sanding, especially the parameter $\mathrm{R}_{\mathrm{z}}$. With a compression ratio of only $10 \%$, sanding may cause the densified layers in the wood surface to be destroyed. The results among treatment groups also showed that the value of higher temperature and shorter duration was roughly equal to that of lower temperature and longer duration. In consequence, the desired surface roughness may be obtained at a higher temperature but shorter duration, or at a lower temperature but longer duration. Statistical analysis indicated that treatment temperature was more significant than treatment time on surface roughness.

During the heat treatment process, surface densification reduced the porosity of the wood and made a glossy surface, which decreased the roughness of the wood surface. There was a negative correlation between the roughness and the compression ratio. Previously studies reported that surface roughness of heat-treated wood decreased with increasing treatment temperature and time (Aytin et al. 2015, Bekhta et al. 2014, Ratnasingam et al. 2012). This increase in smoothness or decrease in roughness was very important for many applications of solid wood. It is well known that the larger the surface roughness, the more coatings and adhesive is required. There should be enough coatings and adhesive to fill the valleys and form a continuous adhesive layer of equal thickness. Thus, further studies are needed to establish a correlation between surface roughness and coating material amount. To know which type of surface topography in terms of roughness parameters provides a higher bonding strength and fewer coatings, we might be able to choose appropriate parameters of surface roughness. It is also important to know if sanding is a necessary step.
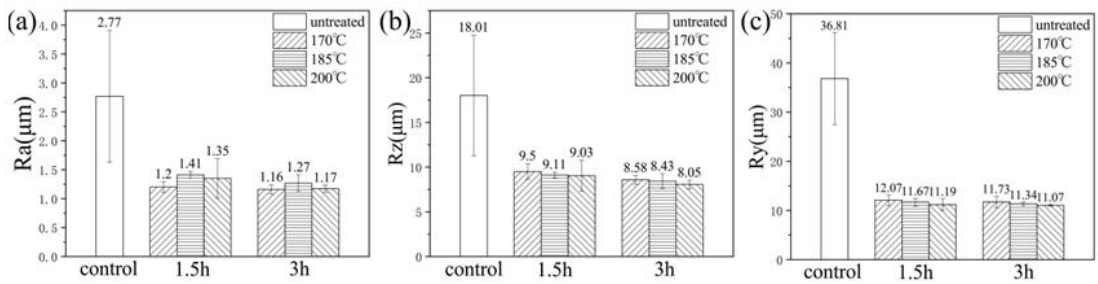

Fig. 4: Surface roughness of rubberwood (before sanding): (a) $R_{a}$, (b) $R_{z}$, and (c) $R_{y}$.
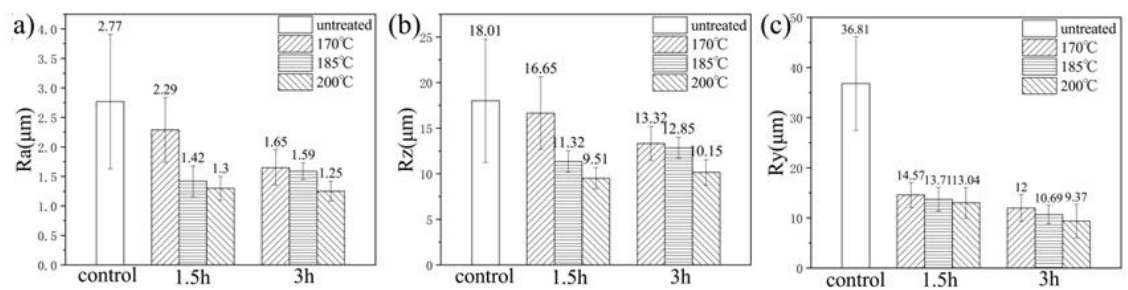

Fig. 5: Surface roughness of rubberwood (after sanding): (a) $R_{a}$, (b) $R_{z}$, and (c) $R_{y}$.

\section{Glossiness}

Changes in glossiness parameters (GZL and GZT) of the untreated control group and the treatment group are presented in Fig. 6 (before sanding) and Fig. 7 (after sanding). As shown in Fig. 6 and Fig. 7, the results show that the values of GZL and GZT increased with increasing treatment temperature and time no matter before or after sanding. The glossiness values of the treatment group were higher than those of the untreated control group. While the highest value 
of glossiness is found in the specimens treated at the highest temperature $\left(200^{\circ} \mathrm{C}\right)$ and the longest time $(3 \mathrm{~h})$. A typical finding for glossiness measurements for all specimens is that glossiness values, when measured along the grain, are higher than those measured across the grain. This can be explained by the anatomical structure on the surface of wood. The wood texture is parallel to the long axis of the cell. Then when the light ray enters along the grain, part of the light is refracted from inside the cell along the long axis of the cell, and the other is refracted along the outer wall of the cell. When light enters the vertical texture, the inner diameter of the cell is much smaller than its length. Thus the light is blocked by the inner wall of the cell (He et al. 2016).
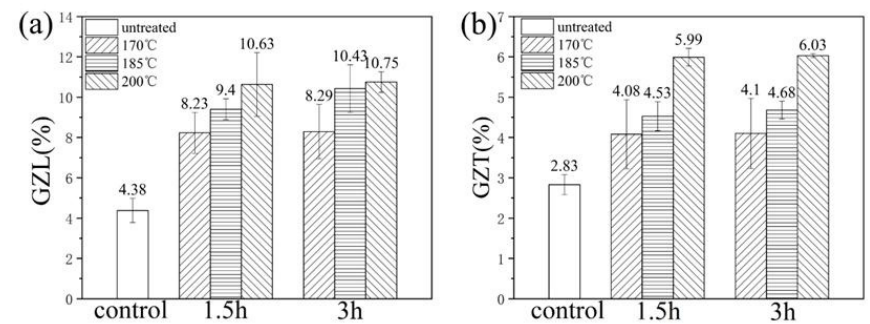

Fig. 6: Surface glossiness of rubberwood (before sanding): (a) GZL, and (b) GZT.
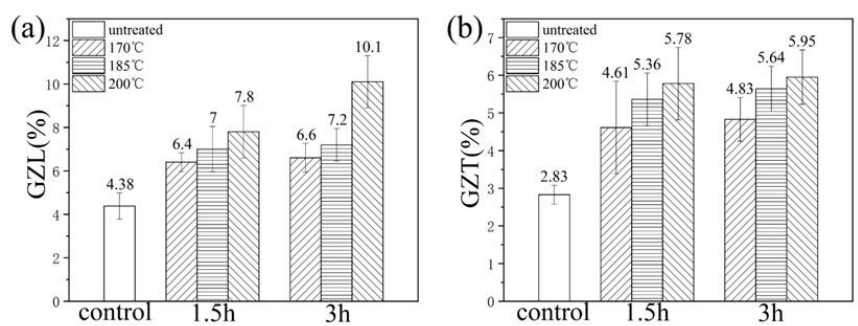

Fig. 7: Surface glossiness of rubberwood (after sanding): (a) GZL, and (b) GZT.

Other studies reported that the glossiness values of heat-treated wood specimens decreased with increasing treatment duration and temperature (Ahmet 2011). This can be explained that heat treatment was combined with wood densification in this study compared with previous studies where only wood heat treatment was applied. Wood compression was the main reason for improving the glossiness of the wood surface. The main reason for the increased glossiness of the wood surface was that the wood was compressed (Bekhta et al. 2014).

Obviously, the natural characteristics of wood have an influence on surface roughness and further on glossiness properties. Smaller roughness values correspond to higher gloss values. The reason is that the increasing roughness means more complex surfaces, and lead to the light scattering more irregular.

\section{CONCLUSIONS}

This study investigated the influences of heat treatment by hot pressing on the surface properties of rubberwood. The results showed that the values of contact angle and glossiness 
increased slightly, and the color of wood changed darker significantly. The values of roughness decreased slightly with increasing heat treatment temperature and duration. The maximum value of roughness was obtained as the samples heat-treated at $200^{\circ} \mathrm{C}$ for $3 \mathrm{~h}$. The heat-treated rubberwood with a warm tone is suitable for some applications. Further research is also needed to establish the quantitative relationships among color, roughness, glossiness and coatings of thermally modified wood.

\section{ACKNOWLEDGEMENT}

The authors are very grateful that this research was financially supported by the Guangdong government science and technology project (Grants No.2017A050501030) and the National Natural Science Foundation of China (Grant No. 31770601).

\section{REFERENCES}

1. Ahmet, A.M.D., Ergun, B., Hilmi, T., 2011: Colour and gloss changes of Socts pine after heat modification. Wood Research 56(3): 329-336.

2. Aleš, U., Kamke, F.A., Sernek, M., Pavlič, M., Kutnar, A., 2013: The wettability and bonding performance of densified VTC beech (Fagus sylvatica L.) and Norway spruce (Picea abies L. Karst.) bonded with phenol-formaldehyde adhesive and liquefied wood. European Journal of Wood and Wood Products 71(3): 371-379.

3. Ayrilmis, N., Kariz, M., Kwon, J.H., Kitek, K.M., 2019: Surface roughness and wettability of surface densified heat-treated Norway spruce (Picea abies L. Karst.). Drvna industrija 70(4): 377-382.

4. Aytin, A., Korkut, S., 2015: Effect of thermal treatment on the swelling and surface roughness of common alder and wych elm wood. Journal of Forestry Research 27(1): 225-229.

5. Bekhta, P., Proszyk, S., Krystofiak, T., Mamonova, M., Pinkowski, G., Lis, B., 2014: Effect of thermomechanical densification on surface roughness of wood veneers. Wood Material Science \& Engineering 9(4): 233-245.

6. Bekhta, P., Proszyk, S., Lis, B., Krystofiak, T., 2014: Gloss of thermally densified alder (Alnus glutinosa Goertn.), beech (Fagus sylvatica L.), birch (Betula verrucosa Ehrh.), and pine (Pinus sylvestris L.) wood veneers. European Journal of Wood and Wood Products 72(6): 799-808.

7. Cademartori, P.H., Missio, A.L., Mattos, B.D., Gatto, D.A., 2015: Effect of thermal treatments on technological properties of wood from two Eucalyptus species. Anais Da Academia Brasilra De Ciências 87(1): 471-481.

8. Cai, S., Zhang, N., Li, K., Li, Y., Wang, X., 2019: Effect of pressurized hot water treatment on the mechanical properties, surface color, chemical composition and crystallinity of pine wood. Wood Research 64(3): 389-400.

9. Cheng, R., Chen, T., Luo, P., Luo, X., 2017: Effects of painting on color and gloss of modified rubberwood. Journal of Southwest Forestry University 37(4): 194-198.

10. Ding, T., Peng, W., Li, T., 2017: Mechanism of color change of heat-treated white ash wood by means of FT-IR and XPS analyses. Journal of Forestry Engineering 2(5): 25-30. 
11. Diouf, P.N., Stevanovic, T., Cloutier, A., Fang, C.H., Blanchet, P., Koubaa, A., Mariotti, N., 2011: Effects of thermo-hygro-mechanical densification on the surface characteristics of trembling aspen and hybrid poplar wood veneers. Applied Surface Science 257(8): 3558-3564.

12. Du, C., Tu, D., Lao, Y., Yang, S., Zhen, F., 2013: The experiment on hot pressing process for thermally treated Populus tomentosa Carr. lumber. China Forestry Science and Technology 27(6): 105-107.

13. Esteves, B., Marques, A.V., Domingos, I., Pereira, H., 2008: Heat-induced colour changes of pine (Pinus pinaster) and eucalypt (Eucalyptus globulus) wood. Wood Science \& Technology 42(5): 369-384.

14. He, T., Luo, J., 2016: Study on the color and luster of twenty species of rosewood. Journal of Forestry Engineering 1(2): 44-48.

15. Jiang, H., Lu, Q., Li, G., Li, M., Li, J., 2019: Research progress in thermal modification of rubber wood. Chinese Journal of Tropical Agriculture 39(4): 93-97.

16. Jie, G., Kim, J.S., Terziev, N., Cuccui, I., Daniel, G., 2018: Effect of thermal modification on the durability and decay patterns of hardwoods and softwoods exposed to soft rot fungi. International Biodeterioration \& Biodegradation 127: 35-45.

17. Korkut, S., Aytin, A., 2015: Evaluation of physical and mechanical properties of wild cherry wood heat-treated using the thermowood process. Maderas. Ciencia y tecnología 17(1): 171-178.

18. Li, X., Cai, Z., Fu, F., Qiao, J., Liu, Y., Yuan, G., 2011: Effects of high temperature thermal treatment on color and wettability of Pseudotsuga menziesii wood. Journal of Central South University of Forestry \& Technology 31(8): 178-182.

19. Li, X., Li, M., Qin, S., Li, J., Lin, W., 2012: Biological durability of heat-treated rubber wood. Scientia Silvae Sinicae 48(4): 108-112.

20. Qin, Z., Liao, M., Zhang, Y., Sun, J., 2019: Wood interface and surface wettability based on contact angle method. Journal of Beihua Univesity 20(2): 249-255.

21. Ratnasingam, J., Ioras, F., 2012: Finishing characteristics of heat treated and compressed Rubberwood. European Journal of Wood and Wood Products 71(1): 135-137.

22. Shukla, S.R., Sharma, S.K., 2014: Effect of high temperature processing under different environments on physical and surface properties of rubberwood (Hevea brasiliensis). Journal of the Indian Academy of Wood Science 11(2): 182-189.

23. Srinivas, K., Pandey, K.K., 2012: Effect of heat treatment on color changes, dimensional stability, and mechanical properties of wood. Journal of Wood Chemistry and Technology 32(4): 304-316.

24. Sun, B., Wang, Z., Liu, J., 2019: Study on color and surface chemical properties of Eucalyptus Pellita wood subjected to thermo-vacuum treatment. Wood Research 64(1): 01-12.

25. Unsal, O., Ayrilmis, N., 2005: Variations in compression strength and surface roughness of heat-treated Turkish river red gum (Eucalyptus camaldulensis) wood. Journal of Wood Science 51(4): 405-409.

26. Yildiz, S., Gezer, E.D., Yildiz, U.C., 2006: Mechanical and chemical behavior of spruce wood modified by heat. Building and Environment 41(12): 1762-1766.

27. Yu, L.L., Tang, Z.Z., Cao, J.Z., Yan, L., 2010: Properties of blue-stain Masson pine after compression and thermal modification. Advanced Materials Research 160-162: 1199-1204.

28. Zhao, X., Tu, D., Chen, C., Zhou, Q. 2019: Prediction of the mechanical properties of thermally-modified rubber wood on the basic of its surface characteristic. Wood Research 64(1): 25-34. 
29. Zhou, Q. Chen, C., Zhao, X., Tu, D., Li, K., 2019: The effect of thermal modification by hot pressing on the some physical and mechanical properties in rubberwood (Hevea brasiliensis). Wood Research 64(2): 361-372.

Zhipeng Zhu, Dengyun Tu*, Zimei Chen, Chuanfu Chen,

Qiangfang Zhou

South China Agricultural University

College of Materials and Energy

Guangzhou

China

*Corresponding author: tudengyun@scau.edu.cn 
